\title{
Computational Drug Design against Ebola Virus Targeting Viral Matrix Protein VP30
}

Arthi Venkatesan
Lavanya Ravichandran
Febin Prabhu Dass J*
Department of Integrative Biology,
Vellore Institute of Technology, Vellore,
Tamil Nadu, India
*email: mail2febin@gmail.com
Keywords:
Drug Design
Ebola Virus
Molecular Docking
Molecular Dynamics Simulation
VP30

\begin{abstract}
Ebola viral disease (EVD) is a deadly infectious hemorrhagic viral fever caused by the Ebola virus with a high mortality rate. Until date, there is no effective drug or vaccination available to combat this condition. This study focuses on designing an effective antiviral drug for Ebola viral disease targeting viral protein 30 (VP30) of Ebola virus, highly required for transcription initiation. The lead molecules were screened for Lipinski rule of five, ADMET study following which molecular docking and bioactivity prediction was carried out. The compounds with the least binding energy were analyzed using interaction software. The results revealed that 6-Hydroxyluteolin and (-)-Arctigenin represent active lead compounds that inhibit the activity of VP30 protein and exhibits efficient pharmacokinetics. Both these compounds are plant-derived flavonoids and possess no known adverse effects on human health. In addition, they bind strongly to the predicted binding site centered on Lys180, suggesting that these two lead molecules can be imperative in designing a potential drug for EVD.
\end{abstract}

Received: June 27th 2019

Accepted: October 10 2019

Published: November 14th 2019

(C) 2019 Arthi Venkatesan, Lavanya Ravichandran, Febin Prabhu Dass J. Published by Institute for Research and Community Services Universitas Muhammadiyah Palangkaraya. This is an Open Access article under the CC-BYSA License (http://creativecommons.org/licenses/by-sa/4.0/). DOI: https://doi.org/10.33084/bjop.v2i2.836.

\section{INTRODUCTION}

Ebola virus (EBOV) is the deadly etiological agent of Ebola viral disease (EVD), earlier known as Ebola hemorrhagic fever. It belongs to the Filovirus family and order Mononegavirales, which contains negative-sense single-stranded RNA with a protective envelope (Geisbert \& Jahrling, 1995). The first outbreak was recorded in 1976, following which EVD outbreaks have proved to be persistently pandemic while the mortality rate is $90 \%$ (Feldmann \& Geisbert, 2011). According to $\mathrm{WHO}$, five strains of EBOV have been identified, causing a total of 25 outbreaks and differentiated based on virulence properties and geographical patterns observed (Picazo \& Giordanetto, 2015). Zaire Ebola virus (ZEBOV), BundibugyoEbola virus (BDBV), Reston Ebola virus (RESTV), Sudan Ebola virus (SUDV), and Taï Forest
Ebola virus (TAFV) are the five strains named after the places affected by the outbreaks. The latest outbreak in 2014 was caused by the most lethal Zaire strain in West Africa, resulting in 11,000 deaths (Baize et al.., 2014). Though the reservoirs are yet to be confirmed, fruit bats, gorilla, antelopes and chimpanzees are considered to be potential hosts for serious transmission (Ascenzi et al., 2008). Followed by this, in humans, it is spread through blood and contact with fluid body secretions. The infection projects itself in two phases with symptoms ranging from fever, fatigue, rashes, vomiting in the early phase, whereas in the late phase hemorrhagic shock occurs eventually resulting in death (Chiappelli et al., 2015). Several diagnostic and laboratory tests are used to examine this deadly virus. Some of the investigations are 
CBC profile, ELISA, RT-PCR and cell culture techniques (Broadhurst et al., 2016).

The filamentous EBOV is composed of approximately 19kb genome (Yu et al., 2017; Zhao, 2016) with genes coding for 4 structural proteins such as VP30, VP35, nucleoprotein $(\mathrm{NP})$, polymerase protein and three membrane-associated proteins such as VP40, glycoprotein and VP24 (Mühlberger, 2007; Easton et al., 2018). The two molecular forms of viral glycoprotein (GP1 \& GP2) in combination with host proteins like Niemann-Pick C1 (NPC1) mediate viral entry (Lee \& Saphire, 2009). Once the viral attachment is complete through the GP1 - host cellular receptor interaction, the virions enter the cell through endocytosis. The threedomain matrix protein VP40 facilitates virion maturation and viral assembly (Hoenen et al., 2005). VP40, which is present profusely, also maintains viral integrity (Passi et al., 2015). VP35 is bi-functional by both being a part of viral replication and also inhibiting IFNs production in the host cell (Basler, 2015).

The nucleoprotein, along with RNA, forms the helical complex whereas VP24 inhibits host STAT1 signaling pathway and mediates nucleocapsid formation. The phosphoprotein VP30, $30 \mathrm{KDa}$ in size, is a major component for viral RNA synthesis and initiates transcription (Cantoni \& Rossman, 2018). The interaction of VP30 with nucleocapsid (NP) brought by the phosphorylation of the $\mathrm{N}$-terminal region, directly affects the transcription process (Biedenkopf et al., 2013). Thus, the VP30 bound NP complex is required for transcription initiation (Weik et al., 2002). The ribonucleoprotein is released from the virion and serves as a template for transcription. Mutation studies reveal that the Phosphorylation sites of VP30 at serine residues is the core requirement for transcription (Martínez et al., 2008). At present, there is no licenced anti-viral treatment available for EVD (Schuler et al., 2017). Factors such as high resistance, the requirement of advanced biosafety levels in clinical trials and the need for further exploration of pathophysiology and complex molecular mechanism makes it highly challenging to combat EBOV (Dhama et al., 2018). Several in silico drug design approaches prove potentially useful for developing anti-viral drugs against EBOV disease as computational biology provides various tools to obtain inherent knowledge of protein structure and interactions to identify potential lead molecules (Schuler et al., 2017). Also, they aim to simulate models of the real world that requires validation through wet-lab experiments.

Most of the Ebola drug design research focuses on targeting VP35 and VP40 because of their importance in viral replication and assembly (Nasution et al., 2018; Roca et al., 2015) but the recent findings describe that intermolecular interactions between VP30 and NP regulate viral mRNA synthesis. NP binds to VP30 at a strongly conserved region in a narrow groove $(\mathrm{Xu}$ et al., 2017). This indicates that VP30 is a promising drug target to block viral replication at the initial stage. Hence, this computational approach identified and analyzes the properties of drug-likeness to filter compounds and were subjected to molecular docking identifying potential inhibitors based on binding energy and interaction properties.

\section{MATERIALS AND METHODS}

\section{Identification of lead molecules}

One hundred and twenty lead molecules with known antiviral properties were selected from literature search (De Clercq, 2015; Huggins et al., 1999; Kouznetsova et al., 2014; Schuler et al., 2017; Shen et al., 2015; Vlietinck et al., 1998). These 120 compounds were from both synthetic and non-synthetic (plant) sources. The SMILES file format of the compounds were retrieved from PubChem database (Kim et al., 2016). SMILES are line notations 
distinct for different structures that are required to obtain two-dimensional and three-dimensional models of the molecules. Later the SMILES format was converted into PDB format using online CORINA server that generates 3D structures (Sadowski et al., 1994).

\section{Protein structure preparation}

The protein crystal structure of Ebola VP30 protein (PDB code: 5DVW) with the resolution of $1.75 \AA$ was retrieved from RCSB Protein Data Bank (PDB), a repository providing crystal structures of biotic macromolecules (Berman et al., 2000). The data in PDB is deposited from various researches based on the results of X-ray crystallography and NMR spectroscopy and is validated using defined standards of stereochemistry (Gore et al., 2017). The water molecules and heteroatoms were removed, and the protein molecule was subjected to energy minimization using Swiss PDB Viewer, a tool for comparative protein analysis (Guex \& Peitsch, 1997).

\section{Analyzing properties of drug-likeness}

All the 120 lead compounds were analyzed for Lipinski rule satisfaction and subjected to ADMET analysis using pkCSM online server (Pires et al., 2015). Lipinski rule of five is the primary criteria to evaluate small lead molecules. This aids in discerning capable drug-like molecules using filters and thus enabling to predict clinical success with higher probability. The five parameters of this rule (Lipinski, 2004), demands the molecular weight to be higher than 500, more than five hydrogen donors and greater than 10 Hydrogen acceptors. Also, the Log P-value should be greater than 5.0 and with ten or more than ten rotatable bonds. The first three parameters correlate with $90 \%$ clinical success. Rotational bonds higher than ten indicate low bioavailability and the ideal value of $\log \mathrm{P}$ or $\log \mathrm{D}$ indicating lipophilicity is between 0-3. Compounds that met these criteria were subjected to ADMET analysis.
ADMET analysis allows to quickly scan through 140 properties to identify lead compounds that are potential with high binding affinity and non-toxic to the human body while absorption and distribution rate are other key factors (Venkatesan et al., 2018). Performing ADMET tests in vivo are highly time-consuming and are not costeffective. Computational tools serve to provide quick screening of toxicity and pharmacokinetic properties. One such tool is pkCSM that represent chemical entities mathematically based on graphical modeling. Some parameters are drug-specific, and in our study parameters such as water solubility, intestinal permeability, not less than 30\%, CaCO-2 permeability that predicts absorption of orally administered drugs, AMES toxicity to test mutagenicity, hepatotoxicity and inhibition of hERG potassium channels which indicates the drug can lead to QT syndrome were considered. Finally, the filtered compounds were subjected to molecular docking study.

\section{Binding site analysis of VP30}

The functional residues of VP30 were analyzed to know the active binding site. Based on mutagenesis analysis ARG179, LYS180, and LYS183 in the secondary nucleoprotein VP30 have been identified as the base residues, which are involved in consorting itself with the nucleocapsid activation of transcription (de La Vega et al., 2015). Mutations in these residues lead to loss of transcription function. The binding site centered on Lys 180 can thus be considered as an expedient target for small inhibitory molecules (Salata et al., 2019). CASTp server (Binkowski et al., 2003) is an online resource for studying surface topography and functional region of proteins used to analysis binding site residues. It depicts concave cavities on protein surfaces and allows the user to explore the interior of the protein providing information about the functional notations. 


\section{Molecular docking}

Molecular docking is an in silico tool that has an increasing significance in drug design (de Ruyck et al., 2016). It allows characterization of protein-ligand interaction at the atomic level and combines the properties of quantum and molecular mechanics (Aminpour et al., 2019). The requisites of docking include the tertiary structure of the protein, pdbqt format of ligand, binding mode and involves four classes of scoring. While docking can be rigid or flexible, we performed rigid docking where the bond length and angles are kept constant. Compounds filtered from ADMET analysis were subjected to docking using AutoDock 4.2 (Forli et al., 2016). Protein preparation is the vital step of docking that requires the removal of water molecules, whereas hydrogen atoms and Kollman charges were added (Xie et al., 2015). The size of the grid box was set to $84 \times 90 \times 92$ to enable docking only within the binding site. A threshold of $-6.5 \mathrm{kcal} / \mathrm{mol}$ was set to select potential inhibitors. The Lamarckian genetic algorithm was used to allow flexible docking between ligands and the receptor. Out of 10 confirmations obtained, the first two compounds with the least binding energy were taken as the best-docked conformations (Garcia-Godoy et al., 2015). The docking results were analyzed by comparing with the control drug BCX4430, an antiviral adenosine analog from BioCryst Pharmaceuticals. It blocks the function of viral polymerase and acts against a broad range of Filovirus by instigating RNA chain termination (Warren et al., 2014). Intramuscular injection of this drug confers protection in rodents exposed to EBOV, thus, making it a controlled drug for docking studies of EBOV (Raj \& Varadwaj, 2016). The control drug was docked with VP30, and its interactions were studied in similar conditions. The docking results were visualized using PyMOL software that delivers high-quality 3D images of the ligand-bound to its protein (Seeliger \& de Groot, 2010). The interacting residues for the control and test compounds were analyzed using LigPlot+, a graphical system that reads 3D coordinates and fosters details of protein-ligand interaction as several two-dimensional figures (Laskowski \& Swindells, 2011).

\section{Bioactivity score prediction}

In silico screening of structural properties related to the pharmacological activity of the selected molecules can aid in understanding their similarity to the known drugs. Molinspiration, a web-based tool was utilized to calculate the bioactivity score of the best-docked complexes and the control drug. Indispensable properties involved for a lead molecule to bind to its receptors of drug target like GPCRs, nuclear receptors, ion channel modulation, inhibition of kinases, proteases and enzymes were calculated (Khan et al., 2017). The input is imported as SMILES structure, and the predicted bioactivity of the screened compounds is given as a numerical score between -5 and +5 .

\section{RESULTS AND DISCUSSION}

\section{ADMET results and active site residues}

This computational study was initiated with the screening of retrieved 120 antiviral compounds for ADMET properties. The results from pkCSM tool for Lipinski rule and ADMET analysis filtered thirty-six lead molecules fulfilling all five criteria of Lipinski rule with acceptable solubility, absorption and possess no known toxic or mutagenic effects were shown in Supplementary Table I. The protein structure of VP30 from PDB is a homodimer with four chains. The binding residues of protein structure from CASTp include ARG168, THR172, ARG179, LYS180, PHE181, SER182, LYS183, HIS215, SER216, ASP217, LYS218, GLY219, GLY220, GLU223, GLU252, SER254, VAL256 and VAL257. These were in par with the earlier studies with 
binding residues centred on LYS180, vital for transcription initiation and nucleocapsid interaction suggested by mutagenesis analysis (Hartlieb et al., 2007).

\section{Molecular docking}

These thirty-six compounds were subjected to molecular docking to anticipate the protein-ligand binding affinities, modes of interaction and inhibition activity. Compounds with the least binding energy are known to be better hits (Venkatesan \& Febin, 2017) and based on the set threshold (binding energy $<-6.5 \mathrm{kcal} / \mathrm{mol}$ ), 10 compounds were selected. Further results from LigPlot+ revealed that two out of ten compounds with PubChemId 5281642 and 64981 are the most effective of all. Both are phytochemicals with previously reported antiviral activity (Vlietinck et al., 1998) and binds at the predicted active binding site forming strong hydrogen bonds. Visualising docking results revealed that ten amino acid residues are in contact with Compound 1 and 13 amino acids with compound 2 .

\section{Binding mode analysis of control compound BCX4430}

Docking VP30 with BCX4430 indicates binding energy of $-4.16 \mathrm{kcal} / \mathrm{mol}$ with 11 amino acids in contact with three hydrogen bonds GLU191, ALA255 and ASP217. Among these residues, only ASP217 belong to the predicted active site. Two more hydrogens bonds were visualized within BCX4430 atoms stabilizing the complex. Residues involved in hydrophobic interactions were ARG179, LYS183, VAL256, SER253, LEU218, GLY220, GLY219, LEU188. The intermolecular energy was $-5.95 \mathrm{kcal} / \mathrm{mol}$, which involves both desolvation and electrostatic energy. This indicates the energy of non-bounded atoms. The total internal energy was $-1.93 \mathrm{kcal} / \mathrm{mol}$ explaining the total of all energy changes and entropy.

\section{Binding mode analysis of compound 1}

Compound 1-6-Hydroxyluteolin (PubChem ID: 5281642) also called as 5,6,7,3', '4'-pentahydroxyflavone is a flavonoid isolated from Valerianella eriocapa (Italian corn salad) and also found in other herbs and spices (Yannai, 2003). Unlike other antiviral compounds, flavones have a wide range of activity. Though the action of flavones in ebola is not fully explored, it is possibly by binding to a glycoprotein of RNA virus (Vlietinck et al., 1998) blocking VP30 interaction with GP necessary for EBOV transcription. The binding energy of this compound was $-7.71 \mathrm{kcal} / \mathrm{mol}$ forming one hydrogen bond within itself and five hydrogen bonds with LYS180, GLU252, LYS218, ASP217 and ARG179 residues that were a part of predicted binding site of VP30. The hydrophobic interactions of ligand were with ARG179, LYS180, PHE181, HIS215 and SER216 of VP30. The intermolecular energy was $-7.99 \mathrm{kcal} / \mathrm{mol}$ with the total internal energy being $-1.37 \mathrm{kcal} / \mathrm{mol}$.

\section{Binding mode analysis of compound 2}

The second compound (-)-Arctigenin (PubChem ID: 64981) is a lignanolide of the dibenzyl butyrolactone type and is known to block HIV-1 viral replication in human cell line experiments (Vlietinck et al., 1998). It is isolated from certain plants of Asteraceae and possesses antiviral and anticancer effects (Afendi et al., 2012). With a docking score of $-7.65 \mathrm{kcal} / \mathrm{mol}$, it formed three hydrogen bonds with active site residues LYS180, GLU252 and LYS218. Hydrophobic interactions with ARG179, HIS215, HIS215, GLU252, SER182, ARG179, PHE181, LYS180, SER182 and PHE181. The intermolecular energy was $10.04 \mathrm{kcal} / \mathrm{mol}$, and the total internal energy change was $-1.97 \mathrm{kcal} / \mathrm{mol}$. The docking results for the control compound and the above discussed best hits are summarized as presented in Table I followed by Figure 1 visualizing the interactions of compounds with VP30. 
Table I. Molecular docking results of control and the best two test compounds

\begin{tabular}{|c|c|c|c|c|c|}
\hline 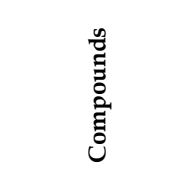 & 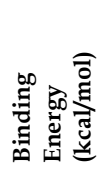 & 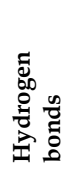 & 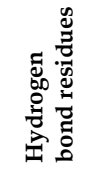 & 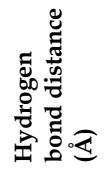 & 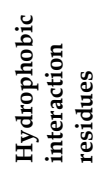 \\
\hline $\begin{array}{l}\text { BCX4430 } \\
\text { (Control) }\end{array}$ & -4.16 & 5 & $\begin{array}{l}\text { Glu191 } \\
\text { Ala255 } \\
\text { Asp217 }\end{array}$ & $\begin{array}{l}2.71 \\
2.87 \\
3.04 \\
2.76 \\
2.87\end{array}$ & $\begin{array}{c}\text { Arg179 } \\
\text { Lys183 } \\
\text { Val256 } \\
\text { Ser253 } \\
\text { Leu218 } \\
\text { Gly220 } \\
\text { Gly219 } \\
\text { Leu188 }\end{array}$ \\
\hline Hydroxyluteolin & -7.71 & 6 & $\begin{array}{c}\text { Lys180 } \\
\text { Glu252 } \\
\text { Lys218 } \\
\text { Asp217 } \\
\text { Arg179 }\end{array}$ & $\begin{array}{l}2.75 \\
2.72 \\
3.11 \\
2.82 \\
2.88 \\
3.03\end{array}$ & $\begin{array}{l}\text { Arg179 } \\
\text { Lys180 } \\
\text { Phe181 } \\
\text { His215 } \\
\text { Ser216. }\end{array}$ \\
\hline (-)-Arctigenin & -7.65 & 3 & $\begin{array}{l}\text { Lys180 } \\
\text { Glu252 } \\
\text { Lys218 }\end{array}$ & $\begin{array}{l}3.23 \\
2.75 \\
2.76\end{array}$ & $\begin{array}{l}\text { Arg179 } \\
\text { His215 } \\
\text { His215 } \\
\text { Glu252 } \\
\text { Ser182 } \\
\text { Arg179 } \\
\text { Phe181 } \\
\text { Lys180 } \\
\text { Ser182 } \\
\text { Phe181 }\end{array}$ \\
\hline
\end{tabular}

a

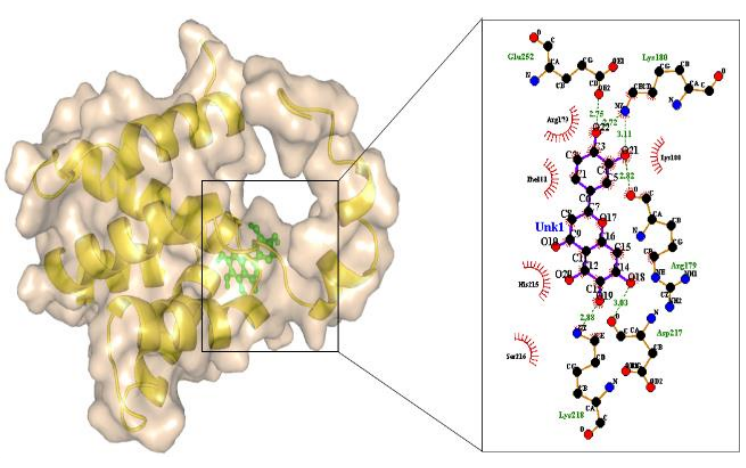

b

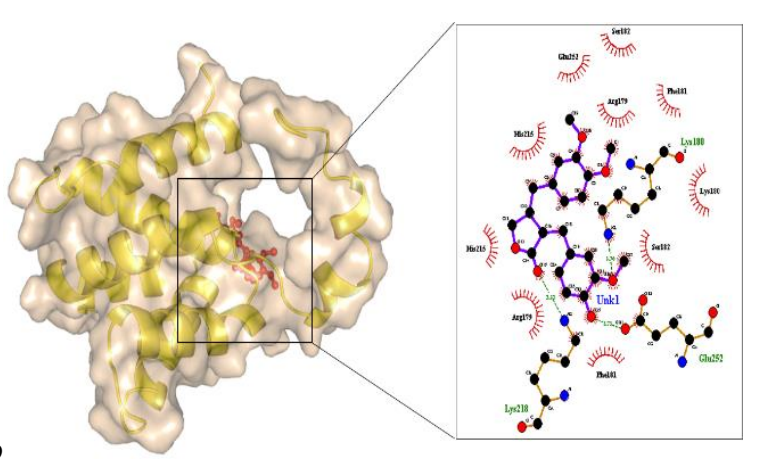

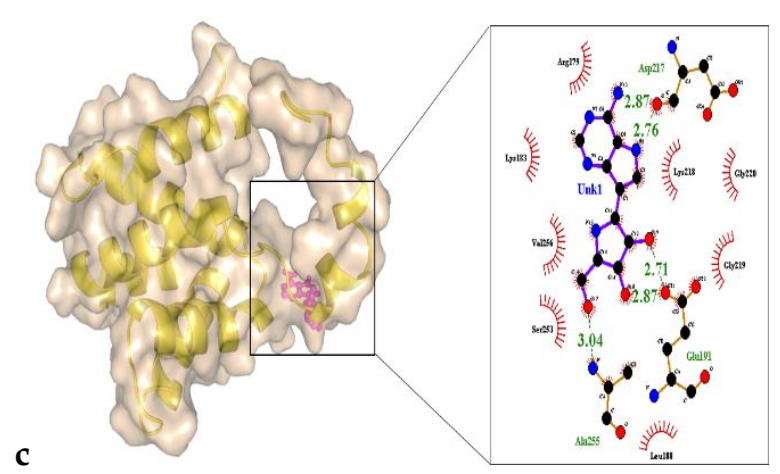

Figure 1. The ribbon structure of VP30 docked with (a) BCX4430, (b) 6-Hydroxyluteolin and (c) (-)-Arctigenin shown as ball and stick appearance (left) and their respective interacting residues (right).

\section{Bioactivity score prediction}

In general, bioactivity score of more than 0.0 indicates the complex is active whereas if the score is between -5.0 and 0.0 the compound is moderately active and if the score is less than -5.0 it is probably inactive. The scores for the test compounds are listed in Table II, which indicates that both these test compounds possess bioactive properties of potential drugs as all the scores were above -5.0 and 0.0 (Joshi et al., 2018).

Table II. Molecular docking results of control and the best two test compounds

\begin{tabular}{|c|c|c|c|c|c|c|}
\hline $\begin{array}{l}\bar{\Xi} \\
\bar{\Xi} \\
\stackrel{0}{0} \\
\text { : }\end{array}$ & 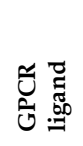 & 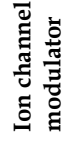 & 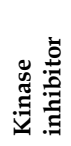 & 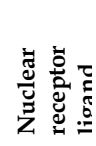 & 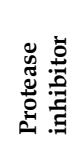 & 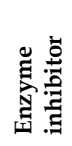 \\
\hline BCX4430 & 0.58 & 0.28 & 0.58 & -0.74 & 0.09 & 1.39 \\
\hline $\begin{array}{l}\text { 6- } \\
\text { Hydroxyluteolin }\end{array}$ & -0.07 & -0.17 & 0.26 & 0.25 & -0.27 & 0.25 \\
\hline (-)-Arctigenin & 0.22 & -0.02 & 0.00 & 0.13 & 0.10 & 0.20 \\
\hline
\end{tabular}

In the current scenario, EBOV-host interactions are still being explored where it is challenging to develop effective drugs and vaccines against EVD, and there is no detailed report of pharmacological inhibition against Ebola virus (Yu et al., 2017). The current strategy being symptomatic management emphasizes the need for targeted drug therapy. High throughput drug screening involving lead optimization, ADMET analysis, animal models and clinical trials is time-consuming, cumbersome and cost-ineffective (Sneha \& Doss, 2016). Here is where computational studies substantially aid 
experimental biology in designing potential drugs within a short period.

Several in silico studies for Ebola virus have been reported targeting VP40 and VP35 to inhibit the activity of viral polymerase and viral assembly (Baikerikar, 2017). However, recent advances exploring the role of VP30 in transcription initiation enables it to be an attractive target though there is no much report with this regard. This study aims to explore the drug target potentiality of VP30. Compounds were screened using ADMET analysis and narrowed down for molecular docking. 6Hydroxyluteolin and (-)-Arctigenin were identified as promising lead molecules since they are permeable, nontoxic, non-mutagenic and possess higher binding affinities than the control compound. Therefore, they can bind to the transcription initiation factor VP30 and block viral proliferation at a much earlier stage than the other targets.

Out of the two investigated compounds, 6Hydroxyluteolin had the least binding energy of all and with six hydrogen bonds, which is higher in comparison to the control compound. Higher the number of hydrogen atoms greater is the stability (Saleh \& Elshemey, 2017). Though the compound (-)-Arctigenin formed a lesser number of hydrogen bonds in comparison to BCX4430, it had lower binding energy pointing to the hydrophobic interactions making the compound more favourable for stable binding. The intermolecular energy for both the test compounds was considerably lower than that of the control. Moreover, the bioactive prediction scores again support the properties of their drug-likeness. Notably, plant-derived compounds, especially flavonoids, are potent inhibitors of Ebola viral disease, as suggested by earlier reports (Raj \& Varadwaj, 2016).

\section{CONCLUSION}

With persistent periodical outbreaks, it is a high priority to developing a potential drug to resist Ebola viral disease. In an attempt to explore if VP30, transcription initiation protein of EBOV can function as a potential drug target for structure-based drug design. The study revealed that the two plants derived compounds 6Hydroxyluteolin and (-)-Arctigenin are potential lead molecules with the least binding energy and active biopredictivity scores. However, the solidity and efficiency should be validated using in vivo experimentations and clinical trials. These compounds identified as potential inhibitors of VP30 functional activity can be used for extensive drug design studies against EBOV study shortly.

\section{ACKNOWLEDGMENT}

We sincerely thank the management of Vellore Institute of Technology (VIT), Vellore, India for providing us with the computational lab facility.

\section{REFERENCES}

Afendi, F.M., Okada, T., Yamazaki, M., Hirai-Morita, A., Nakamura, Y., Nakamura, K., Ikeda, S., Takahashi, H., Altaf-Ul-Amin, M., Darusman, L.K., Saito, K., Kanaya, S. 2012. KNApSAcK family databases: integrated metabolite-plant species databases for multifaceted plant research. Plant and Cell Physiology. 53(2):e1. https://doi.org/10.1093/pcp/pcr165

Aminpour, M., Montemagno, C., Tuszynski, J.A. 2019. An Overview of Molecular Modeling for Drug Discovery with Specific Illustrative Examples of Applications. Molecules. 24(9):1693. https://dx.doi.org/10.3390/molecules240916 93

Ascenzi, P., Bocedi, A., Heptonstall, J., Capobianchi, M.R., Di Caro, A., Mastrangelo, E., Bolognesi, M., Ippolito, G. 2008. Ebolavirus and Marburgvirus: insight the Filoviridae family. 
Molecular Aspects of Medicine. 29(3):151-185. https://doi.org/10.1016/j.mam.2007.09.005

Baikerikar, S. 2017. Curcumin and Natural Derivatives Inhibit Ebola Viral Proteins: An In Silico Approach. Pharmacognosy Research. 9(Suppl 1):S15-S22. https://dx.doi.org/10.4103/pr.pr_30_17

Baize, S., Pannetier, D., Oestereich, L., Rieger, T., Koivogui, L., Magassouba, N., Soropogui, B., Sow, M.S., Keita, S., de Clerck, H., Tiffany, A., Dominguez, G., Loua, M., Traore, A., Kolie, M., Malano, E.R., Heleze, E., Bocquin, A., Mely, S., Raoul, H. Caro, V., Cadar, D., Gabriel, M., Pahlmann, M., Tappe, D., Schmidt-Chanasit, J., Impouma, B., Diallo, A.K., Formenty, P., Herp, M.V., Gunther, S. 2014. Emergence of Zaire Ebola Virus Disease in Guinea. New England Journal of Medicine. 371(15):1418-1425. https://doi.org/10.1056/NEJMoa1404505

Basler, C.F. 2015. Innate Immune Evasion by Filoviruses. Virology. 479-480:122-130. https://doi.org/10.1016/j.virol.2015.03.030

Berman, H.M., Westbrook, J., Feng, Z., Gilliland, G., Bhat, T.N., Weissig, H., Shindyalov, I.N., Bourne, P.E. 2000. The Protein Data Bank. Nucleic Acids Research. 28(1):235-242. https://doi.org/10.1093/nar/28.1.235

Biedenkopf, N., Hartlieb, B., Hoenen, T., Becker, S. 2013. Phosphorylation of Ebola Virus VP30 Influences the Composition of the Viral Nucleocapsid Complex: Impact on Viral Transcription and Replication. Journal of Biological Chemistry. 288(16):11165-11174. https://dx.doi.org/10.1074/jbc.M113.461285

Binkowski, T.A., Naghibzadeh, S., Liang, J. 2003. CASTp: Computed Atlas of Surface Topography of proteins. Nucleic Acids Research. 31(13):33523355. https://doi.org/10.1093/nar/gkg512

Broadhurst, M.J., Brooks, T.J.G., Pollock, N.R. 2016. Diagnosis of Ebola Virus Disease: Past, Present, and Future. Clinical Microbiology Reviews. 29(4):773-793. https://dx.doi.org/10.1128/CMR.00003-16

Cantoni, D., Rossman, J.S. 2018. Ebolaviruses: New roles for old proteins. PLoS Neglected Tropical Diseases. 12(5):e0006349. https://dx.doi.org/10.1371/journal.pntd.000 6349
Chiappelli, F., Bakhordarian, A., Thames, A.D., Du, A.M., Jan, A.L., Nahcivan, M., Nguyen, M.T., Sama, N., Manfrini, E., Piva, F., Rocha, R.M., Maida, C.A. 2015. Ebola: translational science considerations. Journal of Translational Medicine. 13:11. https://dx.doi.org/10.1186/s12967014-0362-3

De Clercq, E. 2015. Ebola virus (EBOV) infection: Therapeutic strategies. Biochemical Pharmacology. 93(1):1-10. https://doi.org/10.1016/j.bcp.2014.11.008

de La Vega, M.A., Wong, G., Kobinger, G.P., Qiu, X. 2015. The multiple roles of sGP in Ebola pathogenesis. Viral Immunology. 28(1):3-9. https://doi.org/10.1089/vim.2014.0068

de Ruyck, J., Brysbaert, G., Blossey, R., Lensink, M.F. 2016. Molecular docking as a popular tool in drug design, an in silico travel. Advances and Applications in Bioinformatics and Chemistry. 9:111.

https://dx.doi.org/10.2147/AABC.S105289

Dhama, K., Karthik, K., Khandia, R., Chakraborty, S., Munjal, A., Latheef, S.K., Kumar, D., Ramakrishnan, M.A., Malik, Y.S., Singh, R., Malik, S.V.S., Singh, R.K., Chaicumpa, W. 2018. Advances in Designing and Developing Vaccines, Drugs, and Therapies to Counter Ebola Virus. Frontiers in Immunology. 9:1803. https://dx.doi.org/10.3389/fimmu.2018.0180 3

Easton, V., McPhillie, M., Garcia-Dorival, I., Barr, J.N., Edwards, T.A., Foster, R., Fishwick, C., Harris, M. 2018. Identification of a small molecule inhibitor of Ebola virus genome replication and transcription using in silico screening. Antiviral Research. 156:46-54. https://doi.org/10.1016/j.antiviral.2018.06.00 3

Feldmann, H., Geisbert, T.W. 2011. Ebola haemorrhagic fever. Lancet. 377(9768):849-862. https://doi.org/10.1016/S01406736(10)60667-8

Forli, S., Huey, R., Pique, M.E., Sanner, M., Goodsell, D.S., Olson, A.J. 2016. Computational proteinligand docking and virtual drug screening with the AutoDock suite. Nature Protocols. 11(5):905-919.

https://dx.doi.org/10.1038/nprot.2016.051 
Garcia-Godoy, M.J., Lopez-Camacho, E., Garcia-Nieto, J., Nebro, A.J., Aldana-Montes, J.F. 2015. Solving Molecular Docking Problems with MultiObjective Metaheuristics. Molecules. 20(6):10154-10183.

https://dx.doi.org/10.3390/molecules200610 154

Geisbert, T.W., Jahrling, P.B. 1995. Differentiation of filoviruses by electron microscopy. Virus Research. 39(2-3):129-150. https://doi.org/10.1016/0168-1702(95)000801

Gore, S., Garcia, E.S., Hendrickx, P.M.S., Gutmanas, A., Westbrook, J.D., Yang, H., Feng, Z., Baskaran, K., Berrisford, J.M., Hudson, B.P., Ikegawa, Y., Kobayashi, N., Lawson, C.L., Mading, S., Mak, L., Mukhopadhyay, A., Oldfield, T.J., Patwardhan, A., Peisach, E., Sahni, G., Sekharan, M.R., Sen, S., Shao, C., Smart, O.S., Ulrich, E.L., Yamashita, R., Quesada, M., Young, J.Y., Nakamura, H., Markley, J.L., Berman, H.M., Burley, S.K., Velankar, S., Kleywegt, G.J. 2017. Validation of Structures in the Protein Data Bank. Structure. 25(12):19161927.

https://doi.org/10.1016/j.str.2017.10.009

Guex, N., Peitsch, M.C. 1997. SWISS-MODEL and the Swiss-PdbViewer: an environment for comparative protein modeling. Electrophoresis. 18(15):2714-2723.

https://doi.org/10.1002/elps.1150181505

Hartlieb, B., Muziol, T., Weissenhorn, W., Becker, S. 2007. Crystal structure of the C-terminal domain of Ebola virus VP30 reveals a role in transcription and nucleocapsid association. Proceedings of the National Academy of Sciences of the United States of America. 104(2):624-629. https://doi.org/10.1073/pnas.0606730104

Hoenen, T., Volchkov, V., Kolesnikova, L., Mittler, E., Timmins, J., Ottmann, M., Reynard, O., Becker, S., Weissenhorn, W. 2005. VP40 octamers are essential for Ebola virus replication. Journal of Virology. 79(3):1898-1905. https://doi.org/10.1128/JVI.79.3.18981905.2005

Huggins, J., Zhang Z.X., Bray, M. 1999. Antiviral drug therapy of filovirus infections: $S$ adenosylhomocysteine hydrolase inhibitors inhibit Ebola virus in vitro and in a lethal mouse model. The Journal of Infectious Diseases.
179(Suppl

https://doi.org/10.1086/514316

1):S240-S247.

Joshi, A., Kumar, R., Sharma, A. 2018. Molecular Docking Studies, Bioactivity Score Prediction, Drug Likeness Analysis of GSK-3 B Inhibitors: A Target Protein Involved in Alzheimer's Disease. Biosciences Biotechnology Research Asia. 15(2):455-467. http://dx.doi.org/10.13005/bbra/2650

Khan, T., Dixit, S., Ahmad, R., Raza, S., Azad, I., Joshi, S., Khan, A.R. 2017. Molecular docking, PASS analysis, bioactivity score prediction, synthesis, characterization and biological activity evaluation of a functionalized 2butanone thiosemicarbazone ligand and its complexes. Journal of Chemical Biology. 10(3):91104. https://dx.doi.org/10.1007/s12154-0170167-y

Kim, S., Thiessen, P.A., Bolton, E.E., Chen, J., Fu, G., Gindulyte, A., Han, L., He, J., He, S., Shoemaker, B.A., Wang, J., Yu, B., Zhang, J., Bryant, S.H. 2016. PubChem Substance and Compound databases. Nucleic Acids Research. 44(D1):D1202-1213. https://doi.org/10.1093/nar/gkv951

Kouznetsova, J., Sun, W., Martinez-Romero, C., Tawa, G., Shinn, P., Chen, C.Z., Schimmer, A., Sanderson, P., McKew, J.C., Zheng, W., GarciaSastre, A. 2014. Identification of 53 compounds that block Ebola virus-like particle entry via a repurposing screen of approved drugs. Emerging Microbes \& Infections. 3(12):e84. https://doi.org/10.1038/emi.2014.88

Laskowski, R.A., Swindells, M.B. 2011. LigPlot+: multiple ligand-protein interaction diagrams for drug discovery. Journal of Chemical Information and Modeling. $\quad$ 51(10):2778-2786. https://doi.org/10.1021/ci200227u

Lee, J.E., Saphire, E.O. 2009. Ebolavirus glycoprotein structure and mechanism of entry. Future Virology. 4(6):621-635. https://doi.org/10.2217/fvl.09.56

Lipinski, C.A. 2004. Lead- and drug-like compounds: the rule-of-five revolution. Drug Discovery Today: Technologies. $\quad \mathbf{1 ( 4 ) : 3 3 7 - 3 4 1 . ~}$ https://doi.org/10.1016/j.ddtec.2004.11.007

Martinez, M.J., Biedenkopf, N., Volchkova, V., Hartlieb, B., Alazard-Dany, N., Reynard, O., Becker, S., 
Volchkov, V. 2008. Role of Ebola Virus VP30 in Transcription Reinitiation. Journal of Virology. 82(24):12569-12573.

https://dx.doi.org/10.1128/JVI.01395-08

Mühlberger, E. 2007. Filovirus replication and transcription. Future Virology. 2(2):205-215. https://dx.doi.org/10.2217/17460794.2.2.205

Nasution, M.A.F., Toepak, E.P., Alkaff, A.H., Tambunan, U.S.F. 2018. Flexible docking-based molecular dynamics simulation of natural product compounds and Ebola virus Nucleocapsid (EBOV NP): a computational approach to discover new drug for combating Ebola. BMC Bioinformatics. 19(Suppl 14):419. https://dx.doi.org/10.1186/s12859-018-23878

Passi, D., Sharma, S., Dutta, S.R., Dudeja, P., Sharma, V. 2015. Ebola Virus Disease (The Killer Virus): Another Threat to Humans and Bioterrorism: Brief Review and Recent Updates. Journal of Clinical and Diagnostic Research. 9(6):LE01-LE08. https://dx.doi.org/10.7860/JCDR/2015/130 62.6100

Picazo, E., Jahrling, P.B. 2015. Small molecule inhibitors of ebola virus infection. Drug Discovery Today. 20(2):277-286.

https://doi.org/10.1016/j.drudis.2014.12.010

Pires, D.E., Blundell, T.L., Ascher, D.B. 2015. pkCSM: Predicting Small-Molecule Pharmacokinetic and Toxicity Properties Using Graph-Based Signatures. Journal of Medicinal Chemistry. 58(9):4066-4072.

https://doi.org/10.1021/acs.jmedchem.5b00 104

Raj, U., Varadwaj, P.K. 2016. Flavonoids as Multi-Target Inhibitors for Proteins Associated with Ebola Virus: In Silico Discovery Using Virtual Screening and Molecular Docking Studies. Interdisciplinary Sciences: Computational Life Sciences. $\quad$ 8(2):132-141. https://doi.org/10.1007/s12539-015-0109-8

Roca, A., Afolabi, M.O., Saidu, Y., Kampmann, B. 2015. Ebola: A holistic approach is required to achieve effective management and control. Journal of Allergy and Clinical Immunology. 135(4):856-867.

https://dx.doi.org/10.1016/j.jaci.2015.02.015
Sadowski, J., Gasteiger, J., Klebe, G. 1994. Comparison of Automatic Three-Dimensional Model Builders Using 639 X-ray Structures. Journal of Chemical Information and Computer Sciences. 34(4):1000-1008.

https://doi.org/10.1021/ci00020a039

Salata, C., Calistri, A., Alvisi, G., Celestino, M., Parolin, C., Palu, G. 2019. Ebola Virus Entry: From Molecular Characterization to Drug Discovery. $\quad$ Viruses. 11(3):274. https://dx.doi.org/10.3390/v11030274

Saleh, N.A., Elshemey, W.M. 2017. Structure-based drug design of novel peptidomimetic cellulose derivatives as HCV-NS3 protease inhibitors. Life Sciences. 187:58-63. https://doi.org/10.1016/j.lfs.2017.08.021

Schuler, J., Hudson, M.L., Schwartz, D., Samudrala, R. 2017. A Systematic Review of Computational Drug Discovery, Development, and Repurposing for Ebola Virus Disease Treatment. Molecules. 22(10):E1777. https://doi.org/10.3390/molecules22101777

Seeliger, D., de Groot, B.L. 2010. Ligand docking and binding site analysis with PyMOL and Autodock/Vina. Journal of Computer-Aided Molecular Design. 24(5):417-422. https://dx.doi.org/10.1007/s10822-010-93526

Shen, Z., Lou, K., Wang, W. 2015. New small-molecule drug design strategies for fighting resistant influenza A. Acta Pharmaceutica Sinica B. 5(5):419-430.

https://doi.org/10.1016/j.apsb.2015.07.006

Sneha, P., Doss, C.G.P. 2016. Gliptins in managing diabetes - Reviewing computational strategy. Life $\quad$ Sciences. 166:108-120. https://doi.org/10.1016/j.lfs.2016.10.009

Venkatesan, A., Febin, P.D.J. 2017. Deciphering molecular properties and docking studies of hepatitis C and non-hepatitis $C$ antiviral inhibitors - A computational approach. Life Sciences.

174:8-14.

https://doi.org/10.1016/j.lfs.2017.02.014

Venkatesan, A., Rambabu, M., Jayanthi, S., Febin, P.D.J. 2018. Pharmacophore feature prediction and molecular docking approach to identify novel anti-HCV protease inhibitors. Journal of Cellular 
Biochemistry.

119(1):960-966.

https://doi.org/10.1002/jcb.26262

Vlietinck, A.J., De Bruyne, T., Apers, S., Pieters, L.A. 1998. Plant-derived leading compounds for chemotherapy of human immunodeficiency virus (HIV) infection. Planta Medica. 64(2):97109. https:/ / doi.org/10.1055/s-2006-957384

Warren, T.K., Wells, J., Panchal, R.G., Stuthman, K.S., Garza, N.L., Van Tongeren, S.A., Dong, L., Retterer, C.J., Eaton, B.P., Pegoraro, G., Honnold, S., Bantia, S., Kotian, P., Chen, X., Taubenheim, B.R., Weich, L.S., Minning, D.M., Babu, Y.S., Sheridan, W.P., Bavari, S. 2014. Protection against filovirus diseases by a novel broad-spectrum nucleoside analogue BCX4430. Nature. 508(7496):402-405. https://doi.org/10.1038/nature13027

Weik, M., Modrof, J., Klenk, H.D., Becker, S., Mühlberger, E. 2002. Ebola virus VP30-mediated transcription is regulated by RNA secondary structure formation. Journal of Virology. 76(17):8532-8539.

https://doi.org/10.1128/jvi.76.17.8532-

8539.2002

Xie, H., Li, Y., Yu, F., Xie, X., Qiu, K., Fu, J. 2015. An Investigation of Molecular Docking and Molecular Dynamic Simulation on Imidazopyridines as B-Raf Kinase Inhibitors. International Journal of Molecular Sciences. 16(11):27350-27361.

https://dx.doi.org/10.3390/ijms161126026

Xu, W., Luthra, P., Wu, C., Batra, J., Leung, D.W., Basler, C.F., Amarasinghe, G.K. 2017. Ebola virus VP30 and nucleoprotein interactions modulate viral RNA synthesis. Nature Communications. 8:15576.

https://doi.org/10.1038/ncomms15576

Yannai, S. 2003. Dictionary of Food Compounds with CDROM: Additives, Flavors, and Ingredients. Boca Raton: Chapman \& Hall/CRC. https://doi.org/10.1201/9781420068450

Yu, D.S., Weng, T.H., Wu, X.X., Wang, F.X.C., Lu, X.Y., Wu, H.B., Wu, N.P., Li, L.J., Yao, H.P. 2017. The lifecycle of the Ebola virus in host cells. Oncotarget. 8(33):55750-55759. https://doi.org/10.18632/oncotarget.18498

Zhao, Y. 2016. Towards Structural Based Drug Development for Ebola Virus Disease. Journal of Chemical Biology \& Therapeutics. 1(1):e102. https://doi.org/10.4172/2572-0406.1000e101 